AperTO - Archivio Istituzionale Open Access dell'Università di Torino

\title{
Emotion understanding: A cross-cultural comparison between Italian and German preschoolers
}

\section{This is the author's manuscript}

Original Citation:

\section{Availability:}

This version is available http://hdl.handle.net/2318/141842

since

Published version:

DOI:10.1080/17405629.2014.890585

Terms of use:

Open Access

Anyone can freely access the full text of works made available as "Open Access". Works made available under a Creative Commons license can be used according to the terms and conditions of said license. Use of all other works requires consent of the right holder (author or publisher) if not exempted from copyright protection by the applicable law. 


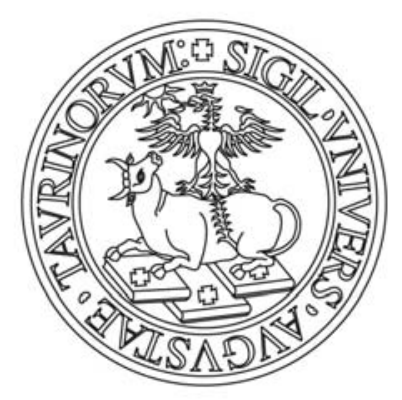

\section{UNIVERSITÀ DEGLI STUDI DI TORINO}

This is an author version of the contribution published on:

Questa è la versione dell'autore dell'opera:

Molina, P.; Bulgarelli, D.; Henning, A.; Aschersleben, G. (2014). Emotion understanding: A cross-cultural comparison between Italian and German preschoolers. European Journal of Developmental Psychology, 11 (5), $592-$ 607, DOI: 10.1080/17405629.2014.890585

The definitive version is available at:

La versione definitiva è disponibile alla URL:

http://www.tandfonline.com/doi/abs/10.1080/17405629.2014.890585? src=recsy s\#.U677kLF-h-Q

(settembre 2014) 


\begin{abstract}
Italy and Germany belong to the Latin and the Germanic cultural cluster, respectively, and show e.g. diverse languages, religious practices, rearing styles and socialization goals. Given potential cultural differences in the developmental goals of independence and interdependence, the present work sought to explore developmental differences between Italian and German 3- to 6-year-old children's understanding of emotion assessed by the Test of Emotion Comprehension. On average, Italian $(\mathrm{N}=114)$ compared to German $(\mathrm{N}=108)$ preschoolers mastered more TEC components at the ages 3 and 5. On component level, however, the samples only differed on the component Hiding: more Italian compared to German preschoolers understood that expressed and felt emotion may differ. Cultural differences within the Western industrial world thus likely regard specific components rather than overall competence. Results will be discussed in relation to cultural belonging, controlling for maternal educational level, presence of siblings and multilingualism.
\end{abstract}

Keywords: emotion comprehension; cultural differences; TEC (Test of emotion comprehension). 


\section{Emotion understanding: A cross-cultural comparison between Italian and German pre-schoolers}

Emotion Understanding (EU) is one component of social cognition and emotional competence, and refers to the way in which persons understand, predict and explain their own and others' emotions (Denham, 1998; Harris, 1989; Saarni, 1999). From early on, children perceive and adequately react to another person's emotional state (Klinnert, Campos, Sorce, Emde, \& Svejda, 1983). Although emotional expressions are directly perceivable, the knowledge about how emotions relate to situations and mental processes helps us to better understand and react to other people's actions (Harris, 1989).

While the development of EU has been largely studied (see e.g. Denham, Wyatt, Bassett, Echeverria, \& Knox, 2009; Pons, Harris \& de Rosnay, 2004), only few studies addressed the question to what extent EU and its development are universal or culturally mediated. First cross-cultural studies on this topic (Avis \& Harris, 1991; Vinden, 1999) focused on non-Western cultures: results were discordant and differences in, e.g., literacy or school attendance did not systematically explain these observed differences in EU.

In cultural psychology, the concepts of individualism and collectivism were proposed to describe systems of meanings, values and practices that characterize different cultures (Hofstede, 1991; Killen \& Wainryb, 2000). Within the broader distinction between individualism and collectivism, that are mostly referred to societies, two cultural pathways to universal tasks of human development have been proposed: independence and individuation on the one hand, and interdependence and group membership on the other hand. These two dimensions co-exist in every culture, but cultures differ in the relative importance given to each of them (Greenfield, Keller, Fuligni, \& Maynard, 2003; Suizzo, 2007). Individuals come into contact with their specific cultural orientation towards independence and interdependence facing multifaceted social interactions and experiences (Killen \& Wainryb, 2000). In particular, family is the organism mediating independence and interdependence pathways in 


\section{EMOTION UNDERSTANDING IN ITALY \& GERMANY}

the child's construction of her individual self (Kagitcibasi, 2009). This assumption is supported by cross-cultural studies on parental behavior and childrearing values and beliefs, revealing cultural specificities in parenting between neighboring cultures across and within countries (Bornstein, 2012; Harkness \& Super, 1996).

Importantly, dimensions of individualism and collectivism and independence and interdependence are associated with the social and emotional domain of life. While interdependence seems to be associated with higher social intelligence (Greenfield et al., 2003), individualism correlated positively with higher emotional expressivity and negatively with lower inter-individual variability in expressing emotions (Matsumoto et al., 2008). It seems reasonable that especially knowledge regarding the expression of emotion, e.g., display rules, should be acquired earlier in collectivistic cultures. However, there is mixed evidence for differences between collectivistic (e.g., Japan, India) and individualistic countries (e.g., Great Britain) in understanding the distinction between real and apparent emotion. For example, Indian Marathi children were better at understanding this distinction compared to English children (Joshi \& MacLean, 1994); this difference was, however, limited to Indian Marathi girls and specific to task stories involving interactions between an adult and a child and the concealment of negative emotions. Also, Japanese preschoolers' understanding of the distinction between real and apparent emotion was not accelerated compared to that of English preschoolers, although Japanese children are socialized at an earlier age with the rules for the display of emotions in public (Gardner, Harris, Ohmoto, \& Hamazaki, 1988; Harris, Donnelly, Guz, \& Pitt-Watson, 1986).

Stronger evidence for differences in EU between collectivistic and individualistic cultures was reported by studies comparing Chinese and Euro-American preschoolers (Chen, 2009; Wang, 2008). Chinese preschoolers were outperformed by Euro-American children in tasks assessing the role of an external reminder on emotion, but they were better in understanding how moral reasoning impacts on emotion, that is in attributing negative 


\section{EMOTION UNDERSTANDING IN ITALY \& GERMANY}

feelings to a transgressor and positive feelings to a rule abider (Chen, 2009). Overall, these works suggest an influence of culture on children's development in understanding emotion. However, comparison is difficult, especially comparison of developmental progression, due to differences in ages, methods and aspects of EU assessed.

A more recent line of research set out to assess whether there is a developmental progression in the understanding of the components of EU (e.g., Albanese \& Molina, 2008; Janke, 2008; Pons et al., 2004). Harris and Pons developed a theoretical model identifying nine components of EU that emerge between 3 and 11 years, and developed the Test of Emotion Comprehension (TEC: Pons \& Harris, 2000) to assess their developmental progression. The TEC was originally tested on a sample of 1003 - to 11-year-old British children (Pons et al., 2004). The hierarchical analyses revealed that the nine components are arranged in groups of three: within each group, an equivalent level of difficulty can be observed. The components relevant to emotion recognition (I), to external causes of emotions (II) and to the role of memory (V) comprise the lower level of difficulty. The understanding of the role of desires (III), beliefs (IV) and the difference between felt and displayed emotion (VII) is acquired at a subsequent stage. Finally, the understanding of emotion regulation (VI), the moral dimension of emotions (IX) and emotional ambivalence (VIII) reflect a higher level of mental elaboration attained only in late childhood. Empirical findings outlined a developmental pattern that slightly differs from the theoretically postulated order (reflected by the roman number identifying each component). 
Table 1 : Percentage of correct response to the TEC components in total and preschoolers' samples from different cultures

\begin{tabular}{|c|c|c|c|c|c|c|}
\hline \multirow{7}{*}{$\begin{array}{l}\text { TEC } \\
\text { components }\end{array}$} & & & \multicolumn{4}{|c|}{ Countries } \\
\hline & \multirow{2}{*}{\multicolumn{2}{|c|}{$\begin{array}{l}\text { United Kindom } \\
\text { Pons et al., } 2004\end{array}$}} & \multirow{2}{*}{\multicolumn{2}{|c|}{$\begin{array}{l}\text { Italy } \\
\text { Albanese \& Molina, } \\
2008\end{array}$}} & \multirow{2}{*}{\multicolumn{2}{|c|}{$\begin{array}{l}\text { Germany } \\
\text { Janke, } 2008\end{array}$}} \\
\hline & & & & & & \\
\hline & $\begin{array}{l}\text { Total } \\
\text { sample }\end{array}$ & $\begin{array}{l}\text { Preschoolers } \\
N=40\end{array}$ & $\begin{array}{l}\text { Total } \\
\text { sample }\end{array}$ & $\begin{array}{l}\text { Preschoolers } \\
\mathrm{N}=332\end{array}$ & $\begin{array}{l}\text { Total } \\
\text { sample }\end{array}$ & $\begin{array}{l}\text { Preschoolers } \\
N=40\end{array}$ \\
\hline & $\mathrm{N}=100$ & $3 / 5$ years & $\mathrm{N}=$ & $3-5$ years & $\mathrm{N}=80$ & $3 / 5$ years \\
\hline & $3 / 5 / 7 / 9 / 11$ & & 967 & & $3 / 5 / 8 / 10$ & \\
\hline & years & & $\begin{array}{l}3-11 \\
\text { vears }\end{array}$ & & years & \\
\hline I-Recognition & 84.00 & 65.00 & 89.00 & 69.00 & 81.50 & 62.50 \\
\hline II-Ext. Cause & 79.00 & 47.50 & 77.00 & 38.00 & 66.25 & 32.50 \\
\hline III-Desire & 66.00 & 37.50 & 67.00 & 33.70 & 62.50 & 27.50 \\
\hline IV-Belief & 68.00 & 30.00 & 68.00 & 41.30 & 58.75 & 32.50 \\
\hline$V$-Reminder & 81.00 & 62.50 & 67.00 & 38.30 & 57.50 & 32.50 \\
\hline VI-Regulation & 39.00 & 10.00 & 42.00 & 19.00 & 55.00 & 30.00 \\
\hline VII-Hiding & 59.00 & 27.50 & 67.00 & 40.00 & 47.50 & 20.00 \\
\hline VIII-Mixed & 39.00 & 10.00 & 42.00 & 15.30 & 47.50 & 25.00 \\
\hline IX-Morality & 40.00 & 15.00 & 60.00 & 36.70 & 41.25 & 25.00 \\
\hline
\end{tabular}

A first study assessed children's rank ordering of success in all nine components of EU with the TEC in a non-Western culture (Tenenbaum, Visscher, Pons and Harris, 2004). Some discrepancy was found between their rank order and that of the British original sample (Pons et al., 2004). More British children understood that reflecting upon a situation may result in conflicting emotions (VIII Mixed), but more Quechua children appreciated that a photograph may reactivate a past emotion (V Reminder).

While differences between Western and non-Western cultures seem to be rather obvious, cultural differences between European countries may be less pronounced. In Europe, the TEC has been recently employed to assess EU also in Italian (Albanese \& Molina, 2008) and German children (Henning \& Aschersleben, submitted; Janke, 2008; Table 1). The Italian standardization of the TEC comprised 967 3-11-year-old children (Albanese \& Molina, 2008) while a German study comprised 80 3-10-year-old German children (Janke, 2008). In both samples, children's performance showed a general similarity with the British rank ordering of 


\section{EMOTION UNDERSTANDING IN ITALY \& GERMANY}

the TEC components (Pons et al., 2004). Differences were due to the inversion of the positions of the components V Reminder and III Desire: at each age level, British children were better in the component V Reminder and Italian and German children in the component

III Desire (Table 1). These findings suggest that also within the Western industrialized world, differences in the development of EU may regard specific components rather than overall ranking order. The current work therefore aims at extending the line of research on cultural influence on the development of EU by focusing on two countries within Europe: Italy and Germany.

Research in several scientific domains suggests that European countries may be grouped into cultural clusters, with cultural differences being greater between than within clusters. Italy belongs to Latin Europe, with France, Spain, Portugal, Monaco, Romania, Moldova, San Marino and the Vatican. Countries in Latin Europe share common historical origins (the Roman Empire), linguistic backgrounds (Latin and the Romance language), and the majority of them share the Catholic religion (Friedman \& Pérez-Perdomo, 2003). In contrast, Germany groups together with those European countries whose languages share Germanic origins: Great Britain, Austria, Flanders regions of Belgium, Denmark, Ireland, Lichtenstein, Luxemburg, Norway, Sweden, and The Netherlands. Importantly, these two areas also differ in parental style being oriented more towards interdependence (Latin cluster) or independence (Germanic cluster). For example, in respect to the first years of life, Italian mothers tend to discourage their children's autonomous behaviors (e.g., exploring the environment or playing without an adult) as well as independent daily routines (e.g., selffeeding and self-sleeping; New, 1988). On the contrary, German parents tend to avoid presence at bedtime and promote self-soothing strategies (Valentin, 2005). Also, when observed interacting on playgrounds, German parents tend to interact less with their 2- to 7year-old children than Italian and French parents (Best, House, Bernard, \& Spicker, 1994). A recent study compared maternal daily routines and their preschool children's adaptive 


\section{EMOTION UNDERSTANDING IN ITALY \& GERMANY}

behaviors in Italian and Austrian/German families in South Tyrol, an Italian region in which these two cultural groups coexist (Taverna, Bornstein, Putnick, \& Axia, 2011).

Austrian/German mothers promoted more child autonomy than Italian mothers and their children were more involved in daily activities fostering independence, such as personal care, domestic tasks and community responsibilities. Differences still endure during adolescence: parents' time allocation to different leisure activities (e.g., watching TV, socializing) is more positively associated to children's time allocation in Italy than it is in Germany or France, that is, the role of parents for the time children spent for various activities is greatest for Italy (Cardoso, Fontainha, \& Monfardini, 2008).

Given previous work on differences in the development of EU as a function of relative importance of an interdependent versus an independent orientation in cultural orientation, the aim of the current work was to directly compare Italian and German preschoolers' performance on the TEC and to explore potential differences on the level of both total score and single components.

Previous works show that children's social-cognitive development is influenced by family background such as parental education level and siblings, as well as by children's language development (e.g., Cutting \& Dunn, 1999; Perner, Ruffman \& Leekam, 1994; Pons, Lawson, Harris \& de Rosnay, 2003). Also, variables on family background need to be taken into account when cultural differences are explored (Bronfenbrenner, 1979). Maternal educational level, presence of siblings and children's multilingualism were therefore taken into account in the analyses. 


\section{Method}

\section{Participants}

The Italian preschoolers involved in the current study were part of the Italian standardization sample of ToM Storybooks (Molina \& Bulgarelli, 2012). The data of the German sample pertains to a previously reported study on the relation between preschooler's EU and their Theory of Mind competence (Henning \& Aschersleben, subm.). The Italian sample comprised 114 3- to 6-year-old children (Table 2). An additional child was tested but excluded for uncooperative behaviour. Children came from a large city in the north of Italy. All children were reported to speak Italian. Parents were contacted through their child's kindergarten and gave their written consent. As recompense for participation, plenary meetings were organized to share the research results with parents and educators.

The German sample comprised 108 3- to 6-year-old children (Table 2). Additional 7 children were tested but excluded from analysis because of developmental disorder $(n=1)$ and uncooperative behaviour $(n=6)$. Participants came from a medium-sized city in the southwest of Germany. All children were reported to speak German. Parents were contacted through their child's kindergarten and gave their written consent. As recompense for participation, children were given a small gift (i.e., bouncy ball), and also kindergartens received a gift.

As can be seen in Table 2, the gender ratio, the presence of sibling(s), and frequency of multilingualism ( 2 or more languages) did not differ between samples. However, parents were younger and maternal education was higher in the German compared to the Italian sample. Children differed in age only in the group of 6-year-olds: German children were on average 4 months older than Italian children. 
Table 2 : Description and comparison of the Italian and German samples

\begin{tabular}{|c|c|c|c|c|c|}
\hline \multirow[b]{2}{*}{ Variable } & \multicolumn{2}{|l|}{ Italian } & \multicolumn{2}{|l|}{ German } & \multirow[b]{2}{*}{ Chi2 (two-tailed) } \\
\hline & $N(\%)$ & & $N(\%)$ & & \\
\hline Sample size & 114 & & 108 & & \\
\hline Girls & $60(53)$ & & $56(52)$ & & $.01, \mathrm{df}=1, p=.907$ \\
\hline Only child & $45(40)$ & & $41(38)$ & & $.05, \mathrm{df}=1, p=.817$ \\
\hline Multilingual & $28(25)$ & & $25(23)$ & & $.06, \mathrm{df}=1, p=.805$ \\
\hline \multicolumn{6}{|l|}{ Maternal Education } \\
\hline Primary schooling & $63(55)$ & & $38(35)$ & & \\
\hline Secondary schooling & $37(33)$ & & $53(49)$ & & $10.05, \mathrm{df}=2, p=.007$ \\
\hline \multirow[t]{2}{*}{ University degree } & $9(8)$ & & $14(13)$ & & \\
\hline & $M(S D)$ & range & $M(S D)$ & range & t-test (two-tailed) \\
\hline Child age (months) & $57.5(11.3)$ & $38-76$ & $60.4(11.9)$ & $37-82$ & $\begin{array}{l}t(220)=1.90, p= \\
.059^{\mathrm{a}}\end{array}$ \\
\hline Maternal age (years) & $36.5(5.6)$ & $24-46$ & $34.4(5.6)$ & $18-46$ & $t(217)=2.69, p=.008$ \\
\hline Paternal age (years) & $40.0(6.0)$ & $25-53$ & $38.0(6.4)$ & $21-53$ & $t(202)=2.32, p=.022$ \\
\hline
\end{tabular}

\section{Materials and Procedure}

Test of Emotion Comprehension (TEC). The Italian (Albanese \& Molina, 2008) and German version (Janke, 2006) of the TEC were administered, respectively (for a detailed description of the test, see Pons et al., 2003; Pons et al., 2004). Children were individually tested in a separate room in their kindergarten (4 kindergartens in Italy and 8 in Germany). 4 experimenters in Germany and 11 in Italy administered the test. No differences were found by experimenters. The German children also performed the sentence comprehension subscale of 


\section{EMOTION UNDERSTANDING IN ITALY \& GERMANY}

the SETK (Grimm, 2001) and the German version of the Theory of Mind Scale (Hofer \& Aschersleben, 2007) in the same 40-minutes administration session. The German childrens' average T-value for sentence comprehension score was in the normal range of development $(M=49.70, S D=8.55, n=108)$. The Italian children performed the TEC and the Leiter-R (Roid \& Miller, 2002) in two different sessions. No differences were found by order of test administration. The children's non-verbal intelligence quotient was in the normal range of development $(M=100.22, S D=12.06)$.

\section{Scoring}

Test of Emotion Comprehension (TEC). The Italian and German versions of the TEC share the same computing system, except for the scoring of Component III (Desire). Whereas the German score for III Desire includes all four test questions (coca cola and lettuce items), the Italian score only includes the last two test questions (lettuce items). The Italian scoring procedure was also applied to the German sample such that the current Italian sample could be compared with the Italian TEC norms. Success rates of Italian children in the current study were not significantly different from those in the Italian standardization sample of the TEC, when controlling for the maternal educational level.

Socio-demographic questionnaire. Parents were also asked to complete a questionnaire on socio-demographic background. Given the differences between the Italian and German educational systems, the CASMIN Classification (Braun \& Müller, 1997) was adopted to code parental educational level. Maternal as well as paternal education was assessed on an ordinal scale ranging from 0 to 2 , according to whether parents did not complete secondary schooling (0), completed secondary schooling (1), or received an academic degree (2) (Table 2). For each sample, maternal and paternal educational level were positively related (Italian: $r=.263, p<.01$; German: $r=.398, p<.001$ ). Information in regard is missing for 5 mothers (4\%) and 3 fathers (3\%) in the Italian sample and for 7 


\section{EMOTION UNDERSTANDING IN ITALY \& GERMANY}

mothers $(6 \%)$ and 14 fathers $(13 \%)$ in the German sample. Given the greater number of missing data for fathers and the more frequent use of maternal education in previous work as control, maternal education was used in the analyses.

Children's linguistic background was derived from parental report. Although all children were reported to speak the language the TEC was administered in (Italian or German, respectively), it was assessed whether the language of the TEC was also the child's first language or not. Italian parents were asked the child's first language and where they were born. German children were defined 'German native speaker' if parents indicated German as their child's first language. In addition, it was assessed whether children were monolinguals (i.e., only spoke Italian or German, respectively) or if they also spoke a language other than Italian or German, respectively. Italian children were defined 'monolingual', if both their Italian parents' were born in Italy, or 'multilingual', if at least one parent was born outside Italy; German children were defined 'monolingual', if German was the only language spoken at home, or 'multilingual' if one or more languages other than German were spoken at home. Given these differences in questionnaires, the following two variables were used to control for child language in the analyses on cultural comparison: 1) accordance between the child's first language and the language the TEC was administered in, 2) monolingualism vs. multilingualism.

\section{Results}

\section{Development of emotion understanding in Italian and German pre-schoolers}

The observed TEC score ranged from 0 to $8(M=3.70, S D=1.96, n=114)$ in the Italian sample, and from 0 to $7(M=3.33, S D=1.70, n=108)$ in the German sample, with no child succeeding on all 9 components in either group (Table 3). 
Table 3 : Ranking order, number (percentage) of Italian and German children passing each TEC component as well as average number of components (standard deviations) passed in each culture

\begin{tabular}{|c|c|c|c|c|c|}
\hline \multirow[t]{2}{*}{ TEC task } & \multicolumn{2}{|c|}{ Italian $(n=114)$} & \multicolumn{2}{|c|}{ German $(n=108)$} & \multirow[b]{2}{*}{$\mathrm{Chi}^{2}(d f=1)$} \\
\hline & Rank & Number $(\%)$ & Rank & Number $(\%)$ & \\
\hline I- Recognition & 1 & $82(71.9)$ & 1 & $82(75.9)$ & $.46, p=.498$ \\
\hline II-External Cause & 2 & $57(50.0)$ & 2 & $61(56.5)$ & $.94, p=.333$ \\
\hline III-Desire ${ }^{a}$ & 4 & $49(43.0)$ & 3 & $48(44.4)$ & $.05, p=.826$ \\
\hline IV-Belief & 6 & $42(36.8)$ & 6 & $30(27.8)$ & $2.08, p=.149$ \\
\hline$V$-Reminder & 5 & $48(42.1)$ & 4 & $38(35.2)$ & $1.12, p=.290$ \\
\hline VI-Regulation & 8 & $34(29.8)$ & $7 / 8$ & $29(26.9)$ & $.24, p=.623$ \\
\hline VII-Hiding & 3 & $55(48.2)$ & 5 & $32(29.6)$ & $8.07, p=.005$ \\
\hline VIII-Mixed & 9 & $15(13.2)$ & 9 & $11(10.2)$ & $.47, p=.491$ \\
\hline$I X-$ Moral $^{b}$ & 7 & $40(35.1)$ & $7 / 8$ & $29(26.9)$ & $1.76, p=.185$ \\
\hline$M(S D)$ & & $3.7(2.0)$ & & $3.3(1.7)$ & \\
\hline
\end{tabular}

Note. All $p$-values are two-tailed. The Chi-square test for each component refers to all 4 cells resulting from crossing the two factors culture $\mathrm{X}$ success (pass, fail).

${ }^{\text {a }}$ Salad task only.

${ }^{\mathrm{b}}$ Second test question only.

Preliminary descriptive analyses confirmed that data distribution was normal in each Italian and German age group (Kolmogorov-Smirnov tests: Italian: skewness: -.10 - .97, kurtosis: - $.03-2.11$, all $p>.10$; German: skewness: $-1.08-.25$, kurtosis: $-1.20-1.48$, all $p$ $>.10)$

A 2 (Cultural Group) X 2 (Gender) X 4 (Age: 3, 4, 5, and 6 years) ANOVA was performed on the total TEC score. There was a significant effect of age $(F(3,221)=36.46, p$ $<.001)$ and culture $(F(1,221)=9.39, p<.01)$. There was no other significant main effect or 


\section{EMOTION UNDERSTANDING IN ITALY \& GERMANY}

interaction (all $p$-values $>.20$ ). In both the Italian and German sample, the total TEC score grew with children's age, but on average, Italian children outperformed German children (Graph 1).

\section{Graph 1 : Trend of TEC total scores in the Italian and German samples}

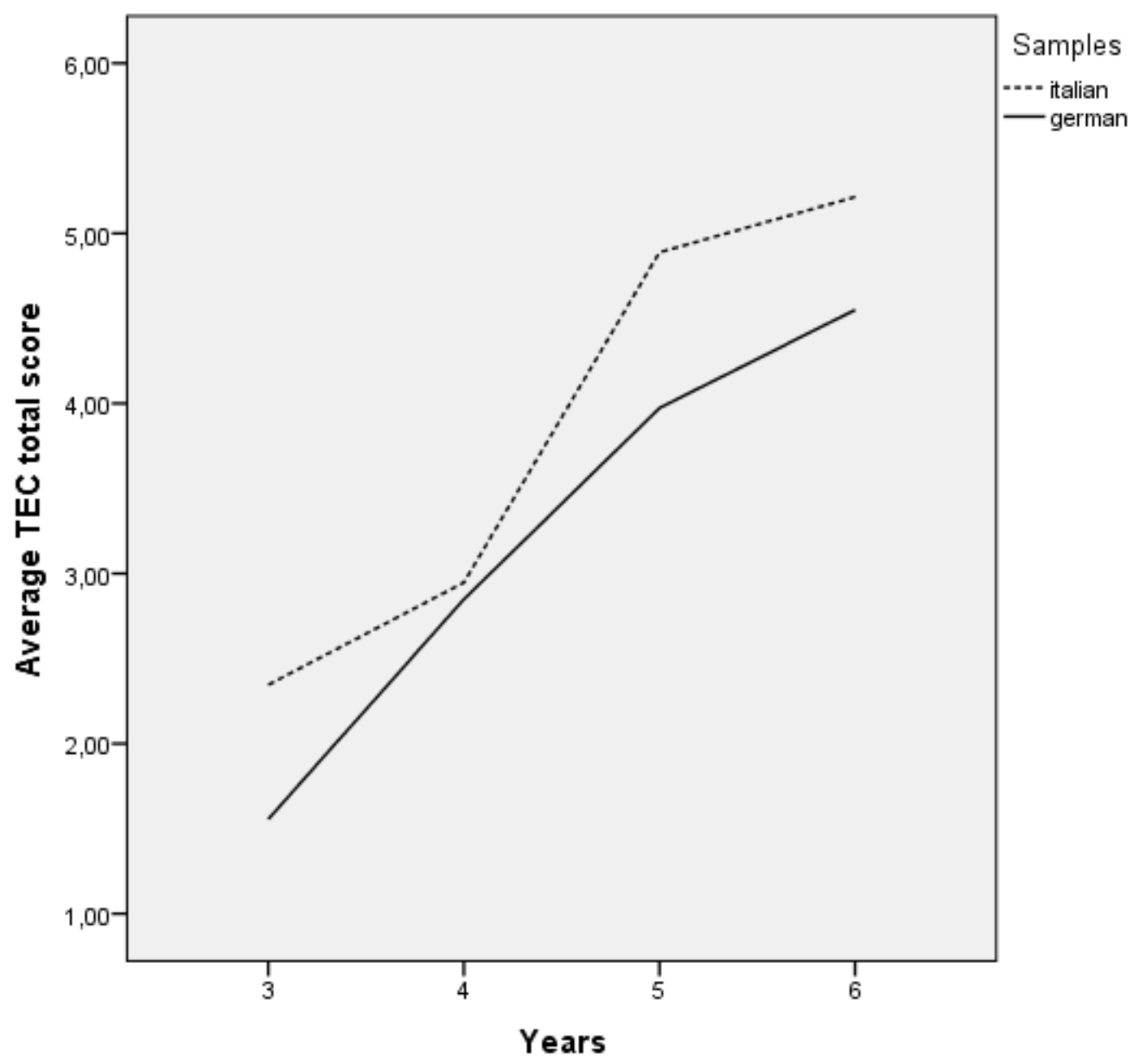

Post hoc tests using the Bonferroni correction revealed three different age groups: 3 years $(M$ $=2.0, S D=1.3), 4$ years $(M=2.9 ; S D=1.6)$ and $5-6$ years $(M=4.6, S D=1.0)$. Also, Italian three-year-olds' TEC score was significantly higher than the German ones $(t(42)=2.18, p<$ .05 ; Italian: $M=2.3, S D=1.3$; German: $M=1.6, S D=1.1$; , the same was true for the fiveyear-olds $(t(71)=2.56, p<.05$; Italian: $M=4.9, S D=1.5$; German: $M=4.0, S D=1.8)$. There 
EMOTION UNDERSTANDING IN ITALY \& GERMANY

were no significant differences between Italian and Germans 4- and 6-year-olds (both $p$ values $>.20)$.

\section{Control on variables that can potentially differentiate the two cultural groups}

To test the influence of socio-demographic variables on cultural difference, a regression analysis was performed with the total TEC score as dependent variable. In model 1, children's age in months, maternal educational level and presence of siblings as predictors were entered in a first step, and cultural group as predictor was entered in a second step (Italian children were coded as "0", German children as "1"). Given that linguistic background varied for children in both samples, we controlled for the possible influence of linguistic factors: the regression was rerun excluding children whose first language was not the language of the TEC (model 2), and excluding children who were multilingual (model 3). In model 4, multilingualism was added as additional predictor in the first step and the analysis computed on the whole sample. In all models, only age and cultural group significantly predicted children's EU (Table 4). The unique contributions to the total variance of the total TEC score were $34 \%$ and $6 \%$ for age and cultural group, respectively. 
Table 4 : Relation of children's total TEC score and cultural group controlling for the possible influence of socio-demographic variables on cultural difference.

\begin{tabular}{llcccc}
\hline \multicolumn{1}{l}{ Independent variables } & & $B$ & S.E. of $B$ & $\beta$ & $s r^{2}$ \\
\hline \multicolumn{4}{c}{ Model 1: TEC scale score (DV); N $=214 ; R^{2}=.337$ (change in $\left.R^{2}=.039\right)$} \\
$\begin{array}{l}\text { Age (in months) } \\
\begin{array}{l}\text { Maternal educational } \\
\text { level }\end{array}\end{array}$ & First step & $.09^{* *}$ & .01 & .56 & .34 \\
$\begin{array}{l}\text { Siblings } \\
\text { Cultural group }\end{array}$ & First step & .25 & .01 & .09 & .01 \\
\hline
\end{tabular}

Model 2: TEC scale score (DV); $\mathrm{N}=186^{\mathrm{a}} ; R^{2}=.325\left(\right.$ change in $\left.R^{2}=.045\right)$

$\begin{array}{llllll}\text { Age (in months) } & \text { First step } & .09 * * & .01 & .58 & .39\end{array}$

Maternal educational level

$\begin{array}{lllll}\text { First step } & .24 & .17 & .09 & .01\end{array}$

\begin{tabular}{llcccc} 
Siblings & First step & .27 & .22 & .07 & .01 \\
Cultural group & Second step & $-.80^{*}$ & .22 & -.22 & .07 \\
\hline
\end{tabular}

Model 3: TEC scale score (DV); $\mathrm{N}=166^{\mathrm{b}} ; R^{2}=.38\left(\right.$ change in $\left.R^{2}=.041\right)$

$\begin{array}{llllll}\text { Age (in months) } & \text { First step } & .09 * * & .01 & .58 & .34\end{array}$

Maternal educational

level

$\begin{array}{lllll}\text { First step } & .21 & .18 & .08 & .01\end{array}$

$\begin{array}{llllll}\text { Siblings } & \text { First step } & .37 & .24 & .10 & .01\end{array}$

$\begin{array}{llllll}\text { Cultural group } & \text { Second step } & -.77^{* *} & .24 & .21 & .06\end{array}$

Model 4: TEC scale score (DV); $\mathrm{N}=214 ; R^{2}=.341\left(\right.$ change in $\left.R^{2}=.039\right)$

$\begin{array}{llcccc}\text { Age (in months) } & \text { First step } & .09^{* *} & .01 & .59 & .35 \\ \text { Maternal educational } & \text { First step } & .25 & .16 & .09 & .01 \\ \text { level } & \text { First step } & .35 & .21 & .09 & .01 \\ \text { Siblings } & \text { First step } & -.27 & .24 & -.06 & .01 \\ \text { Multilingualism } & \text { Second step } & -.76^{*} & .21 & -.20 & .06 \\ \text { Cultural group } & & \end{array}$

${ }^{*} p<.05 . * * p<.001$.

${ }^{a}$ Model 2 corresponds to Model 1 run on the subsample of children, whose first language is also the language in which the TEC is administered.

${ }^{\mathrm{b}}$ Model 3 corresponds to Model 1 run on the subsample of monolingual children. 


\section{Differences between Italian and German preschoolers at the level of single TEC components.}

A series of $\chi^{2}$ tests were performed to assess whether relative frequencies of passing or failing a TEC component differed between the two cultural groups. A significant difference was found in component VII Hiding $\left(\chi^{2}(222)=8.07, p<.01\right.$; Table 3$)$. To control for children's age, a binomial logistic regression was conducted, with children's performance on component VII Hiding as dependent variable, and with age in months and cultural group as predictors. Nagelkerke's $R^{2}=.07$ indicated that $7 \%$ of variance was explained by the model. The hit rate of correctly classified children was $65 \%$. Cultural group was significantly related to task performance $(B=-.88$, Wald statistic $=9.39, p<.01)$ as well as age in months $(B=$ .03 , Wald statistic $=4.30, p<.05$ ). Similar to results for the overall TEC score, also for VII Hiding, both cultural group and child age predicted children's success in this component.

\section{Discussion}

The aim of the current study was to explore potential cultural differences in the development of the nine EU components comprised in the TEC, comparing preschoolers from two European countries that show different cultural features: Italy and Germany. In fact, while differences between Western and non-Western cultures seem to be more easily observable, cultural differences between European countries may be less pronounced. Thus, our question was whether children coming from different cultures within the Western industrialized world differ in their development of EU, and if yes, whether differences regard overall performance on the TEC or specific components.

Results suggest that Italian and German children did not differ in their overall ability to understand emotions. However, some differences were present at specific ages or in 


\section{EMOTION UNDERSTANDING IN ITALY \& GERMANY}

specific components. Italian children scored significantly higher than the German ones at 3 and 5 years. Although German children were somewhat older in the 6-year-old group, their total score did not differ from that of Italian 6-year-olds. Children from both cultural groups performed similarly on the different components, except for the component VII Hiding: this is coherent with cultural differences in more individualistic (German) compared to more collectivistic (Italian) cultures. No other variables in addition to age and cultural group differentiated children responses: gender distribution, presences of siblings, and multilingualism. Moreover, the cultural differences observed in the current study are supported by the fact that the two samples were similar with respect to these three sociodemographic variables. Although German parents were younger and have higher formal education than Italian parents, mothers' educational level was not associated with their children's TEC scores.

The present findings are consistent with previous findings on European samples. Italian and British children from 3 to 11 years showed a similar rank ordering in the TEC components, with a local inversion of components III Desire and V Reminder (Albanese \& Molina, 2008; Pons et al., 2004). Similarly, British (Pons et al., 2004) and 3- to 10-year-old German (Janke, 2008) children showed an overall similar rank ordering with a marked local inversion of the component V Reminder.

Which cultural aspects may explain the generally higher performance of the Italian children in the current work, and specifically, their better comprehension of the distinction between real and apparent emotion? Italian parents give more importance to interdependence than German ones (Taverna, et al., 2011): they highly regulate children's routines and foster low autonomy; moreover, Italian parents early socialize their children to kin, show high responsiveness rates to crying (New, 1988), and scarcely promote self-soothing strategies (Valentin, 2005); and still during adolescence, the role of Italian parents in influencing youngsters' time allocation to leisure activities is more pronounced (Cardoso et al., 2008). All 


\section{EMOTION UNDERSTANDING IN ITALY \& GERMANY}

these parenting features can be linked to higher emotional holding that may foster earlier EU in Italian children. This explanation is also coherent with the literature linking interdependence to higher social intelligence (Greenfield et al., 2003). Also, children living in India, an interdependent culture where compliance to adults is a culturally enforced attitude, showed a better performance in a real/apparent emotion task (Joshi \& MacLean, 1994). It is therefore likely that the role of culture, mediated by parenting styles, appeared to be crucial for the display rules in infancy. Still, a relative greater importance given to interdependence does not seem to be linearly associated with EU development: Chinese children live in collectivistic societies, where values of interdependence and membership are important, and yet they systematically showed lower EU performances in the literature, except for the role of morality on emotion (e.g., Chen, 2009). An alternative explanation may be that differences in the motivation to hide emotion underlie these observed differences in understanding hidden emotion. However, the ability to distinguish between real and apparent emotion is not associated with the motivation to hide emotion (Gasselin, Warren \& Diotte, 2002).

With respect to the utility of testing tools, the TEC proved to be a useful instrument to investigate local differences in EU developmental paths, thanks to three main aspects: first, it is designed to quickly evaluate EU across a wide age range, second, it allows to compare performance on different EU components due to similarity in task demand and format, and third, it has been translated in several languages thus allowing to collect data across cultures using the same methodology.

Further cross-cultural studies are needed to better understand differences and commonalities in the development of EU, both in terms of single EU components as well as of developmental progression, and their association with other psychological constructs. Future cross-cultural research should especially focus on those variables that appear to influence EU, such as parenting style: in fact, to our knowledge, studies on cross-cultural differences in EU so far did not directly collect data on parent's rearing style. Particularly, 


\section{EMOTION UNDERSTANDING IN ITALY \& GERMANY}

focusing on independency and interdependency dimensions could be an interesting starting point (see, e.g, Keller, 2002).

\section{Acknowledgments}

Thank you to the psychology undergraduate students of the Empiriepraktikum 20102011 and Annette Brückner and Christoph Kowalski for help with the collection and coding of the German data. Special thanks to Christiane Mink for organizational support. We also thank Bettina Janke for helpful comments regarding the testing procedure and coding of the German version of the Test of Emotion Comprehension. We thank professor Ottavia Albanese and all Italian co-authors of the Italian version of the Test of Emotion Comprehension for making the standardization data available. We are especially grateful to the Kita $\mathrm{gGmbH}$ and to German and Italian kindergarten staff for their support and to the parents and children who participated in the study. The research of Daniela Bulgarelli was partly supported by a grant from Collegio Carlo Alberto and the European Union's Seventh Framework Programme (FP7/2007-2013; grant no. 320116) for the research project FamiliesAndSocieties.

\section{References}

Albanese, O., \& Molina, P. (2008). Lo sviluppo della comprensione delle emozioni e la sua valutazione. La standardizzazione italiana del Test di Comprensione delle Emozioni (TEC) [The development of emotion understanding and its evaluation. The Italian standardization of the Test of Emotion Comprehension (TEC)], Milano: Unicopli.

Avis, J., \& Harris, P. H. (1991). Belief-desire reasoning among Baka children: Evidence for a universal conception of mind. Child Development, 62, 460-467. 
Best, D. L., House, A. S., Barnard, A. E., \& Spicker, B. S. (1994). Parent-Child Interactions in France, Germany, and Italy. The Effects of Gender and Culture. Journal of crosscultural psychology, 25(2), 181-193.

Bornstein, M. H. (2012). Cultural approaches to parenting. Parenting: Science and Practice, $12(2-3), 212-221$.

Braun, M., \& Müller, W. (1997). Measurement of Education in Comparative Research. Comparative Social Research, 16, 163-201.

Bronfenbrenner, U. (1979). The ecology of human development: Experiments by design and nature. Cambridge, MA: Harvard University Press.

Chen, D. (2009). Culture, parent-child conversation, and children's understanding of emotion. (Doctoral dissertation). Available from ProQuest Dissertations and Theses database. (UMI No. 3385011)

Cardoso, A. R., Fontainha, E., \& Monfardini, C. (2008). Children and parents time use: empirical evidence on investment in human capital in France, Italy and Germany. IZA discussion papers, 3815 (http://nbn-resolving.de/urn:nbn:de:101:1-20081127382).

Cutting, A. L., \& Dunn, J. (1999). Theory of mind, emotion understanding, language, and family background: Individual differences and interrelations. Child development, 70(4), 853-865.

Denham, S. A. (1998). Emotional development in young children. New York (NY): Guilford Press.

Denham, S. A., Wyatt, T. M., Bassett, H. H., Echeverria, D., \& Knox, S. S. (2009). Assessing social-emotional development in children from a longitudinal perspective. Journal of Epidemiology and Community Health, 63(Suppl. I), i37-i52.

Friedman, L. M., \& Pérez-Perdomo, R. (2003). Legal culture in the age of globalization: Latin America and Latin Europe. Stanford (C): Stanford University Press. 


\section{EMOTION UNDERSTANDING IN ITALY \& GERMANY}

Gardner, D., Harris, P.L., Ohmoto, M., \& Hamazaki, T. (1988). Japanese children's understanding of the distinction between real and apparent emotion. International Journal of Behavioral Development, 65, 203-218.

Gasselin, P., Warren, M., \& Diotte, M. (2002). Motivation to hide emotion and children's understanding of the distinction between real and apparent emotion. The Journal of Genetic Psychology: Research and Theory on Human Development, 163(4), 479-495.

Greenfield, P. M., Keller, H., Fuligni, A., \& Maynard, A. (2003). Cultural pathways through universal development. Annual Review of Psychology, 54, 461-490.

Grimm, H. (2001). Sprachentwicklungstest für Kinder (SETK 3-5) [Language development test for 3- to 5-year-old children]. Göttingen, Germany: Hogrefe.

Harkness, S., \& Super, C. M. (1996). Parents cultural belief systems: Their origins, expressions, and consequences. New York: Guilford Press.

Harris, P. L. (1989). Children and emotion. Oxford (GB): Blackwell.

Harris, P. L., Donnelly, K., Guz, G. R., \& Pitt-Watson, R. (1986). Children's understanding of the distinction between real and apparent emotion. Child Development, 57, 895-909.

Henning, A., \& Aschersleben, G. The development of emotion understanding in German preschoolers and its relation to desire and belief reasoning. Manuscript submitted for publication.

Hofer, T., \& Aschersleben, G. (2007). 'Theory of Mind'-Skala für 3- bis 5-jährige Kinder [German Theory of Mind-scale for 3- to 5-year-old children] (3rd ed.). Max Planck Institute for Human Cognitive and Brain Sciences, Munich, Germany.

Hofstede, G. (1991). Cultures and organizations: Software of the mind. London: McGrawHill.

Janke, B. (2006). Skala zur Erfassung des Emotionswissens für 3- bis 10-jährige Kinder. Pädagogische Hochschule: Heidelberg. 
Janke, B. (2008). Emotionswissen und Sozialkompetenz von Kindern im Alter von drei bis zehn Jahren. Empirische Pädagogik, 22(2), 127-144.

Joshi, M. S, \& MacLean, M. (1994). Indian and English children's understanding of the distinction between real and apparent emotion. Child Development, 65, 1372-1384.

Kagitcibasi, C. (2009). Autonomy and relatedness in cultural context. Implications for self and family. Journal of Cross-Cultural Psychology, 36(4), 403-422.

Keller, H. (2002). Development as the interface between biology and culture: A conceptualization of early ontogenetic experiences. In H. Keller, Y. Poortinga \& A. Schoelmerich (Eds.), Between culture and biology (pp. 215-240). Cambridge: Cambridge University Press.

Killen, M., \& Wainryb, C. (2000). Independence and interdependence in diverse cultural contexts. New Directions for Child and Adolescent Development, 2000(87), 5-21.

Klinnert, M. D., Campos, J. J., Sorce, J. F., Emde, R. N., \& Svejda, M. (1983). Emotions as behavior regulators: Social referencing in infancy. Emotion: Theory, research and experience, 2, 57-86.

Matsumoto, D., Yoo, S. H., Fontaine, J., Anguas-Wong, A. M., Arriola, M., Ataca, B., ... Grossi, E. (2008). Mapping expressive differences around the world. The relationship between emotional display rules and individualism versus collectivism. Journal of Cross-cultural Psychology, 39(1), 55-74.

Molina, P., \& Bulgarelli, D. (2012). La standardizzazione italiana del test ToM Storybooks: dati preliminary [The Italian standardization of the test ToM Storybooks: preliminary data]. Giornale Italiano di Psicologia, 39(4), 863-879.

New, R. S. (1988). Parent goals and Italian infant care. New Direction for Child Development, $40,51-63$.

Perner, J., Ruffman, T., \& Leekam, S. R. (1994). Theory of mind is contagious: You catch it from your sibs. Child Development, 65(4), 1228-1238. 
Pons, F. \& Harris, P. L. (2000). Test of Emotion Comprehension (TEC). Oxford: Oxford University.

Pons, F., Harris, P. L. \& de Rosnay, M. (2004). Emotion comprehension between 3 and 11 years: Developmental periods and hierarchical organization. European Journal of Developmental Psychology, 1(2), 127-152.

Pons, F., Lawson, J., Harris, P. L., \& de Rosnay, M. (2003). Individual differences in children's emotion understanding: Effects of age and language. Scandinavian Journal of Psychology, 44, 347-353.

Roid, G. H., \& Miller L. J. (2002). Leiter-R: Leiter international Performance Scale-Revised (M. Sabbadini \& F. Galloni, Trad.). Firenze: Giunti OS.

Saarni, C. (1999). The development of emotional competence. New York (NY): Guilford Press.

Suizzo, M. A. (2007). Parents' goals and values for children dimensions of independence and interdependence across four US ethnic groups. Journal of Cross-Cultural Psychology, 38(4), 506-530.

Taverna, L., Bornstein, M. H., Putnick, D. L., \& Axia, G. (2011). Adaptive behaviors in Young Children: A unique cultural comparison in Italy. Journal of Cross-Cultural Psychology, 42(3), 445-465.

Tenenbaum, H. R., Visscher, P., Pons, F., \& Harris, P. L. (2004). Emotional understanding in Quechua children from an agro-pastoral village. International Journal of Behavioral Development, 28(5), 471-478.

Valentin, S. R. (2005). Sleep in German infants - The cult of independence. Pediatrics, $115(1), 269-271$.

Vinden, P. G. (1999). Children's understanding of mind and emotions: A multi-culture study. Cognition and Emotion, 13(1), 19-48.

Wang, Q. (2008). Emotion knowledge and autobiographical memory across the preschool years: A cross-cultural longitudinal investigation. Cognition, 108, 117-135. 